\title{
trabalhanecessärio
}

issn: $1808-799 \mathrm{X}$

ano 5 - número 5 - 2007

\section{AS MUDANÇAS ESTRUTURAIS DO CAPITALISMO RURAL E SUAS IMPLICAÇÕES NA FORMAÇÃO DE TÉCNICOS EM AGROPECUÁRIA: A EXTINÇÃO DA COAGRI/MEC [i].}

\author{
-André Elias Fidelis Feitosa[ii] \\ aeffeitosa@yahoo.com.br
}

\begin{abstract}
"As transformações atuais que ocorrem na agricultura brasileira podem ser entendidas a partir da subordinação crescente das atividades agrícolas às exigências da reprodução e acumulação de capital na Economia" (BESKOW, 1980).
\end{abstract}

\section{Breve Apresentação.}

Este artigo se preocupará em explicitar que, com a denominada "Revolução Verde", ocorrida no Brasil por volta da década de 1960, a lógica de produção capitalista industrial invadiu também o campo, ou seja, esse grande processo de "modernização" da agricultura brasileira retrata de forma inequívoca a ampliação da lógica do processo de produção capitalista, tanto para o campo quanto para a cidade. A partir dessa transformação, fica difícil verificar especificidades de um capitalismo urbano e um rural, principalmente do ponto de vista dos processos de produção.

O resultado, portanto, dessa modernização foi o modelo de complexos agroindustriais, que tinha como característica mais aparente uma forte intervenção do Estado, fosse diretamente nas políticas para o setor, fosse nos programas de financiamento da produção. Assim, na área da Educação, tal intervenção também se expressou na política de formação profissional de nível médio, comandada pela Coordenação do Ensino Agropecuário (COAGRI), órgão inserido na estrutura de Estado, mais especificamente vinculado ao MEC.

Com a superação desse modelo pelo próprio capitalismo, naquilo que Mazzali (2000) denominou de "o processo recente de reorganização agroindustrial", o papel do 
Estado também se modifica e a necessidade de uma política específica para a formação de técnicos em agropecuária passa a inexistir. Portanto, a extinção da COAGRI, assim tentarei demonstrar, é a expressão de um processo de transformação na própria estrutura do capital; expressão esta que se fortalece na recente transformação de Escolas Agrotécnicas Federais em Centros Federais de Ensino (CEFETs).

\section{Conceitos usados para qualificação das mudanças dos processos de} produção da agricultura brasileira.

Para esta parte do texto, usarei como base para a descrição do processo de modernização[iii], vivido pela agricultura brasileira a partir da segunda metade do século passado, o trabalho de Ângela Kageyama et. alii.(1990).

É interessante, portanto, que se façam as mesmas advertências levantadas por esses autores, logo no início do trabalho:

Segundo eles, conceitos como "modernização da agricultura, industrialização da agricultura[iv] e formação de complexos agroindustriais", são tratados equivocadamente como sinônimos. No que pese a extensa citação, entendo que ela, nesse momento, se torna necessária na perspectiva de expor com maior clareza tais diferenças.

Por modernização da agricultura se entende basicamente a mudança na base técnica da produção agrícola. É um processo que ganha dimensão nacional no pós-guerra com a introdução de máquinas na agricultura (tratores importados), de elementos químicos (fertilizantes, defensivos, etc.), mudanças de ferramentas e mudanças de culturas ou novas variedades. É uma mudança na base técnica da produção que transforma a produção artesanal do camponês, à base da enxada, numa agricultura moderna, intensiva, mecanizada, enfim numa nova maneira de produzir. A modernização da agricultura no Brasil é, pois, um processo 'antigo'. (...).

A 'industrialização da agricultura' envolve a idéia de que a agricultura acaba se transformando num ramo de produção semelhante a uma indústria, como uma 'fábrica' que compra determinados insumos e produz matérias-primas para outros ramos da produção. $O$ camponês produzia em 'interação coma natureza' como se esta fosse seu 'laboratório natural'. Trabalhava com a terra com os insumos e ferramentas que tinha a seu alcance, quase sempre produzidos na própria propriedade. A agricultura industrializada, ao contrário, está conectada com outros ramos da produção; para produzir ela depende dos insumos que recebe de determinadas indústrias; e não produz mais apenas bens de consumo final, mas basicamente bens intermediários ou matérias-primas para outras indústrias de transformação. A industrialização da agricultura brasileira é um processo (...), pós65. (...). A partir do momento em que a agricultura se industrializa, a base técnica não pode regredir mais: se regredir a base técnica, também regride a produção agrícola.

O longo processo de transformação da base técnica - chamado de modernização - culmina na própria industrialização da agricultura. Esse processo representa a subordinação da Natureza ao capital que, gradativamente, liberta o processo de produção agropecuária das condições naturais dadas, passando a fabricá-las sempre que se fizerem necessárias.

(...).

(...), no período pós-75 temos a constituição do que vem se chamando de 
complexos agroindustriais. São vários complexos que se constituem, ao mesmo tempo em que a atividade agrícola se especializa continuamente.(...).

\section{(...).}

Esse processo envolve a substituição da economia natural por atividades agrícolas integradas à indústria, a intensificação da divisão do trabalho e das trocas intersetoriais, a especialização das exportações pelo mercado interno como elemento central da alocação dos recursos produtivos no setor agropecuário. (p.113-116; negrito nosso).

Enfatizadas as diferenças, cabe aqui explicitar que o próprio modelo do complexo agroindustrial, no processo histórico, viveu seu momento de estrangulamento, devido às reestruturações últimas vividas pelo capitalismo em nível mundial. A flexibilização também chegou ao campo, o papel do Estado, portanto, se modificou; conseqüentemente as demandas pela formação de profissionais de nível médio para a agricultura tornaram-se outras. Portanto, se faz necessário descortinar o cenário do processo que culmina na extinção da COAGRI e seus recentes desdobramentos.

\section{Revolução Verde e os Complexos Agroindustriais (CAls).}

A partir de meados da década de 1960, a agricultura no Brasil passa por uma transformação, principalmente naquilo que diz respeito à sua organização produtiva[v], que segundo Delgado (1985) apud Mazzali (2000), surge do aprofundamento das relações do setor agrícola com a economia urbano-industrial.

Tratava-se da reformulação da inserção da agricultura no padrão de acumulação, por meio de um processo de modernização, com ênfase:

- na diversificação e aumento da produção, visando enfrentar os desafios da industrialização e da urbanização aceleradas e a necessária elevação das exportações primárias e agroindustriais;

- na transformação da base técnica da agricultura brasileira, com a consolidação do complexo agroindustrial. (MAZZALI, 2000, p.19).

Dessa forma, o processo de industrialização da agricultura, também apelidado de revolução verde[vi], guardou algumas características específicas. O primeiro ponto a ser destacado é que o desenvolvimento das forças produtivas no campo, ocorrido a partir da década de 1960, inseriram no processo de produção agropecuária novas exigências de aumento da produtividade, calcada na incorporação de insumos industrializados, como por exemplo:

- Da indústria química: adubos, fertilizantes, corretivos, inseticidas, germicidas, fungicidas, herbicidas, etc; 
- Da indústria Mecânica: máquinas e implementos agrícolas, tratores, peças de reposição e de manutenção;

- Da indústria de ração: suplementos alimentares, rações especializadas e componentes para formulação de novas rações;

- Da indústria farmacêutica: vermicidas, vacinas, soros, anestésicos e medicamentos em geral para tratamentos veterinários;

- Da indústria de limpeza: material para desinfecção de ambientes coletivos.

Todas essas indústrias ligadas ao ramo "a montante" do processo de produção agrícola. Porém, o processo de industrialização da agricultura não se caracterizava pela incorporação dessa indústria a montante, o processo de escoamento e de processamento da produção também resultou no crescimento, mesmo que pequeno, de uma indústria já instalada e especializada, chamada de indústria "a jusante" (DELGADO, 1985, p. 39 e 40):

- Indústria de produtos alimentares: beneficiamento, moagem, torrefação, conservas, abate de animais frigoríficos, preparação de pescado, resfriamento e preparação de leite e derivados (laticínios), fabricação e refino de açúcar, doces em geral, produtos de padaria, massas alimentares, etc;

- Indústria química: destilação de álcool, óleos vegetais e essências;

- Indústria do fumo;

- Indústria madeireira;

- Indústria de beneficiamento de couros e peles;

- Indústria de bebidas;

- Indústria têxtil: nas etapas de beneficiamento de fibras vegetais e fiação de fibras de origem animal;

- Indústria de celulose.

Assim, "a definição de um perfil industrial do CAI, compondo os seus principais ramos a jusante e a montante da agricultura, é um indicador relevante para que se possa, senão medir, pelo menos estimar uma ordem de magnitude desse complexo industrial". (lbidem, p.38).

No levantamento apresentado por Delgado (1985), o crescimento da indústria a 
montante, avaliada no conjunto das indústrias de transformações, tem sua participação elevada de 2,4\% para 4,0\%, no período de 1970 a 1975 . O que demonstrava uma forte elevação na demanda por esses produtos resultantes dessa indústria por parte do processo de produção agrícola brasileiro, ou seja, essa é uma expressão da modificação que ocorreu na base técnica da produção agrícola durante este período.

Cabe ressaltar, que o crescimento das atividades da indústria a jusante não foi muito expressivo[vii], já que as mesmas não se constituíram em novos ramos durante e após o processo de modernização, porém, como lembra Mazzali (2000) "embora estas não se constituíssem em ramos novos, passaram a ter um novo perfil e ficaram sujeitas a uma nova dinâmica, a partir da transformação da tecnologia industrial, somada à conversão de mercados regionais em mercado nacional, com especial referência à ampliação da concorrência oligopolista".

Em essência, tratava-se, no momento, de tornar a agricultura menos dependente da dotação de recursos naturais, atrelando as suas condições de reprodução à incorporação de insumos e bens de capital gerados em um setor específico da indústria, implicando o estabelecimento de ligações estreitas, concomitantemente à edificação e reorganização das relações com a indústria processadora de produtos agrícolas. (...) A constituição do CAI resultaram, portanto, na conformação de uma nova categoria de agregação, que incorporou interesses situados no âmbito da agricultura propriamente dita, dos setores industriais produtores de insumos e equipamentos para a agricultura e da indústria processadora de produtos agrícolas. (Ibidem, p.21).

Outro fator importante na conformação do modelo de organização agrícola denominado de Complexo Agroindustrial (CAI) foi o forte aparato do Estado na área do financiamento e das políticas de crédito.

Uma das características que marcou esse processo de modernização da agricultura foi o oferecimento pela rede bancária de créditos para o financiamento da compra de pacotes tecnológicos, na perspectiva da ampliação, principalmente da indústria a montante, que a partir desse processo começou a fixar suas atividades no território brasileiro[viii].

Assim, em 1965, é criado o Sistema Nacional de Crédito Rural (SNCR), no bojo da Reforma do Sistema Financeiro, que estabelecia que parte dos recursos captados pelos bancos fosse destinada ao setor agrícola[ix]. (KAGEYAMA et. alii., 1990)

O forte papel do Estado, característica mais geral de todo sistema capitalista desse período (Fordismo-Keynesianismo), se fez presente nas relações de produção agrícola, no Brasil, não somente nas políticas de crédito agrícola, mas também em toda uma correlação de atividades voltadas à assistência e extensão rural[x], "elemento fundamental 
na estratégia de transferência para o setor agrícola de tecnologia gerada na indústria situada a montante da agricultura".(MAZZALI, 2000, p.24).

A partir desse conjunto de políticas, o Estado executou planejamento indicativo, engendrando novas formas de desenvolvimento capitalista na agricultura. De um lado, moldou e aprofundou as relações de integração técnica entre agricultura e indústria, a montante e a jusante. De outro, estimulou a integração de capitais 'mediante a fusão de capitais multisetoriais operando conglomeradamente, processo que é decididamente apoiado pelas políticas de corte multisetorial (comércio exterior, tabelamento de preços, incentivos fiscais etc) e de fomento direto(crédito rural, política fundiária, tecnologia e desenvolvimento rural integrado)'. (DELGADO, 1985 apud MAZZALI, 2000, p.24).

"Em outras palavras, foi o Estado enquanto financiador e articulador dos diferentes interesses que garantia e gerenciava um padrão no direcionamento das relações entre os agentes, conferindo, dessa forma, um dado 'estilo' ao processo de modernização"(MAZZALI, 2000, p.24).

Essa presença/utilização do Estado no processo de construção dos CAls, pôde também ser identificada nas políticas voltadas à formação de técnicos agrícolas de novo tipo, já que o processo de produção agrícola requeria, simultaneamente, profissionais capacitados para as demandas advindas do setor que rapidamente se reestruturava.

\section{O cenário de criação da COAGRI.}

A criação da COAGRI ocorreu definitivamente em 1975, ano que segundo Kageyama et. alii.(1990, p.188) "marca o início da consolidação dos CAls". Para que não se tenha a idéia de que tais datas possam apenas representar uma grande coincidência, nesta parte do trabalho tentaremos demonstrar como a interação entre as políticas agrícolas e as educacionais de formação profissional se complementam, num objetivo maior, ou seja, que estão inseridas no amplo projeto de industrialização da agricultura.

Depois de delineado o cenário de modernização da agricultura pelo qual passou o Brasil, a partir da década de 1960, resta para este momento, esclarecer como as políticas para a formação de "novos" técnicos em Agropecuária articulavam com esta nova demanda.

Com o intuito de compatibilizar o ensino agrícola de $2^{\circ}$ grau com a Lei 5692/71 e com as propostas de modernização da agricultura brasileira, técnicos do Departamento do Ensino Médio (DEM) e especialistas do Departamento de Ensino Agrícola da Secretaria de Educação do Estado de São Paulo elaboraram o Plano de Desenvolvimento do Ensino Agrícola de $2^{\circ}$ grau, segundo o qual

(...) a prioridade de formação de mão-de-obra para atender à conjuntura 
atual do País recai na formação de um técnico que possa colaborar na solução dos problemas de abastecimento, produzindo gêneros de primeira necessidade e matéria-prima de melhor qualidade e de maneira mais econômica para a indústria, procedendo assim como agente de produção. Simultaneamente o mesmo profissional poderá atuar como agente de serviço para atender ao mercado de trabalho junto às empresas que prestam serviços aos agricultores. (Plano Nacional de Desenvolvimento do Ensino Agrícola de $2^{\circ}$ grau, 1973, apud SIQUEIRA, 1987, p.92, negrito nosso).

Ainda no mesmo documento:

Através de cursos profissionalizantes, as escolas de $2^{\circ}$ grau deverão preparar pessoal qualificado a fim de contribuir para:

- melhorar os níveis de produtividade;

- promover especialistas para melhorar a distribuição de renda no meio rural;

- propiciar o eficiente suprimento de produtos agrícolas para um crescente mercado interno;

- garantir o aumento de capital e mão-de-obra para o desenvolvimento econômico geral;

- promover a integração econômica e social pela ampliação da capacidade de absorção de produtos não-agrícolas. (Ibidem)

Este Plano de Desenvolvimento do Ensino Agrícola de $2^{\circ}$ grau foi o que também estabeleceu a proposta do sistema Escola-Fazenda em nível nacional, e, dentre seus objetivos destacarei apenas dois, na perspectiva de demonstrar como a ação do Estado cumpria os objetivos de um projeto maior do capital para a agricultura:

$\left.3^{\circ}\right)$ dar ao estudante recursos para compreender que a agropecuária é uma indústria de produção.

$\left.7^{\circ}\right)$ integrar o técnico agrícola ao processo de desenvolvimento do País, levando-o a perceber a importância de seu trabalho. (Ibidem, p.94, negrito nosso).

Mantendo o mesmo foco, agora no trabalho de Frigotto (1986), podemos perceber a amplitude das ações do Estado nesta fase histórica do desenvolvimento capitalista, "onde a oligopolização do mercado se radicaliza e imprime uma nova forma às relações capitalistas de produção e impele o Estado a tornar-se, forçosamente, um Estado intervencionista, um proprietário particular, como mecanismo de sustentação dos interesses intercapitalistas, dos interesses do capital no seu conjunto". (p.107).

É nesse cenário de grande reestruturação, com o Estado desempenhando o seu papel de interventor, tanto dos processos de produção na agricultura brasileira, quanto nas políticas de formação profissional para a área[xi], que é criada na sua estrutura a COAGRI. 
Portanto, o caráter intervencionista do Estado se irradiava para ações que garantissem a base de sustentação do projeto de "modernização" para agricultura brasileira (modernização capitalista), no caso, na formação de profissionais habilitados a desempenharem as funções necessárias a este projeto. "Naquele momento, (...) o capital atribuía ao poder público o papel de protagonista das ações educacionais formais" (SANTOS, 2004, p.1). Novas bases técnicas de produção, novos agentes dessa produção.

O Plano de Desenvolvimento para o Ensino Agrícola de $2^{\circ}$ grau, na prática, deparou-se com uma série de contradições. O mesmo Estado (que é resultado das disputas de classes, por isso representante da fração hegemônica da burguesia) que propunha tais transformações, também foi o que não proveu financeiramente as escolas, impedindo que as mesmas adquirissem as condições necessárias para alcançarem os objetivos propostos. Porém o que consideramos para este momento do trabalho, é que a criação da COAGRI se deu em meio a um cenário de mudança na estrutura da produção agrícola brasileira, e, por isso, tal criação representa um reflexo dessas transformações mais amplas de um projeto de "desenvolvimentismo".

No entanto, o modelo de desenvolvimento agrícola através dos CAls, no processo histórico sofre seu estrangulamento. Como havia dito no início deste artigo, a flexibilização chega ao campo, e o reflexo desta mudança se materializava com a extinção da COAGRI, eliminando, a partir desse fenômeno, na estrutura de Estado, o órgão que tratava de especificidades do ensino agrícola, visto que o formato de produção agrícola vinha se aproximando do industrial.

\section{A mudança na organização agroindustrial no contexto da extinção da} COAGRI.

Porque o mais interessante na atual situação é a maneira como o capitalismo está se tornando cada vez mais organizado através da dispersão, da mobilidade geográfica e das respostas flexíveis nos mercados de trabalho, nos processos de trabalho e nos mercados de consumo, tudo isso acompanhado por pesadas doses de inovação tecnológica, de produto e institucional. (HARVEY, 2004, p.150 e 151).

Segundo Mazzali (2000), é a partir da segunda metade da década de 1980, que se é capaz de notar um redirecionamento no comportamento dos agentes envolvidos nas atividades agroindustriais. Redirecionamento que também foi dado na política de formação de técnicos agrícolas, visto que tal movimento era reflexo de uma reestruturação mais ampla do próprio capitalismo em nível mundial.

A flexibilidade também chega ao setor que foi denominado por vários autores de complexo agroindustrial, e esta mudança ainda vem ocorrendo de maneira quase que imediata às mudanças ocorridas no sistema industrial, afinal, as transformações já citadas 
dão conta de comprovar a unificação da lógica capitalista, tanto para o campo quanto para cidade. A penetração de capitais de grandes corporações aproximou os setores, antes muito bem definidos por suas atividades fins.

Afinal, como identificar o setor-fim de grandes capitalistas, já que seus capitais estão investidos/distribuídos nos diversos setores da economia? Grandes corporações financeiras e de produção de bens industrializados também estão ligadas aos setores da agroindústria, e o que se tem observado é que na verdade todos estes setores, no recente processo histórico, vão ficando cada vez mais subsumidos a um grande setor: o financeiro [xii].

Assim,

A partir dos anos 80 , a noção de complexo agroindustrial foi colocada em xeque enquanto aparato conceitual para a apreensão da dinâmica do setor, uma vez que os elementos básicos que lhe deram sustentação - um padrão de desenvolvimento tecnológico, que tem por referência os princípios da 'Revolução Verde'; um estilo de inserção da agricultura no mercado internacional e um determinado perfil de intervenção do Estado - sofreram profundas alterações. (MAZZALI, 200, p.35)

Dessa forma, apoiado em Mazzali (2000), destacarei três aspectos que dialeticamente se complementam na perspectiva de descortinar tais mudanças. Usando as mesmas expressões do autor, são eles:

a) As transformações de ordem econômica internacional;

b) As transformações no âmbito tecnológico;

c) Crise fiscal e a desarticulação do aparato de regulação estatal.

Tentarei, portanto, desenvolver minimamente cada um desses aspectos que se articulam entre si.

a) A crise de acumulação do capitalismo mundial, na década de 1970 , requereu dele próprio, ou seja, de seus agentes uma forma de superação. Superação do horizonte de estagnação, visando sua ampliação, através da transferência de atividades desempenhadas pelo Estado diretamente para as mãos da iniciativa privada. Estado que, mesmo dominado pela burguesia, ao mesmo tempo, dada a sua própria conformação de classes em disputa, apresentava obstáculos/contradições que impediam ou atrasavam os projetos de ampliação de acumulação. Setores conquistados via luta dos trabalhadores no período de Estado de Bem Estar Social, como saúde, educação, previdência, e no próprio setor produtivo, detentor de vários monopólios, foram tomados como grandes atrasos ao desenvolvimento das forças produtivas.Nesse processo ganham forças as políticas de 
cunho neoliberal, na perspectiva de um falso, mas aparente "Estado mínimo".

b) Inovações biotecnológicas, microeletrônicas e nas áreas de informação e organização de sistemas, originaram mudanças profundas nos processos de produção agropecuária.

$\mathrm{Na}$ área de produção de alimentos vegetais, o cruzamento genético e o desenvolvimento de novas espécies (transgênicos) produzem impactos diretos no processo produtivo, principalmente na relação de interdependência dos setores a montante e a jusante da agricultura, haja vista que a produção de tais alimentos requer, e se dá sobre, novas bases tecnológicas.

No campo da produção pecuária, mais precisamente da bovinocultura, os "avanços" como a transferência de embriões e a fertilização in vitro (FIV), superam as possibilidades já dadas anteriormente pela inseminação artificial na perspectiva de "melhoria genética" do rebanho brasileiro[xiii].

A topografia realizada através de geoprocessamento, utilizando tecnologia via satélite (GPS), aliada a mecanização agrícola motorizada, dá origem a uma nova forma de produção denominada de "plantio de precisão", cada vez mais difundido e utilizado por latifundiários, para produção de monoculturas de exportação, contribuindo, portanto, para um aumento na produtividade, destacado como diferencial tecnológico para superação concorrencial.

Por isso,

À maior flexibilidade da oferta - capacidade relativa de produzir uma gama muito mais ampla de produtos em uma única planta, obtida por técnicas que põem em xeque os padrões fordistas - associou-se uma maior capacidade de inovação. Ao possibilitar e incentivar a estreita integração das atividades de projeto e desenvolvimento entre uma gama de empresas da cadeia produtiva e ao quebrar a rígida separação entre a concepção e a execução, por meio da descentralização e da ênfase no conhecimento e na polivalência, implantou-se novo padrão de organização.(Ibidem, p.33, negrito nosso)

c) O discurso neoliberal que se apresentou no sentido de dar solução a crise fiscal que se tornou mais aparente, aqui no Brasil, a partir da década de 1980, se calçava em dois aspectos materiais da economia: "dívida pública (interna e externa) elevada e uma poupança pública (diferença entre receita e despesa corrente) persistentemente negativa". (BRESSER PEREIRA, 1992, apud MAZZOLI, 2000, p.33).

Assim, o discurso do "Estado mínimo" se mostrava como solução de uma crise gerada pelo próprio capitalismo. Nesse discurso: o engessamento causado pela estrutura de Estado impedia a ampliação de novos mercados, de novas iniciativas de investimento, em suma, impediam o crescimento da iniciativa privada. Desta forma o Estado, armazém de inúmeras contradições, deveria, para se tornar mais "eficiente", desobrigar-se de 
inúmeras responsabilidades e se desfazer de instituições que "atrapalhavam o funcionamento da máquina, devido ao grande peso causavam".

Considerando que o Estado situava-se no centro do padrão de desenvolvimento agroindustrial, inaugurado em meados dos anos 60, como patrocinador, legitimador e financiador das articulações entre os diferentes agentes econômicos, a desarticulação do seu aparato de regulação, sem que se defina um novo papel, representou uma desorganização dos interesses rurais e, mais significativamente, uma quebra na orientação e sentido do comportamento desses agentes.[xiv] (MAZZALI, 2000, p.34)

É nesse contexto que se inicia uma ampla e contínua reforma de Estado, como na imagem de um balão que perde altitude ou de uma embarcação prestes a afundar, o Estado vai descartando aquilo que a ideologia (neo)liberal considerava que o tornava "pesado". Ao final da década de 1980, instituições como o Instituto de Álcool e Açúcar (IAA), Instituto Brasileiro do Café (IBC), "foram extintas e seus sistemas de regulação comercial e produtiva foram transferidos a outros organismos ou simplesmente extintas" (Ibidem, p.34)

Essa reestruturação que acontece na forma de organização da produção, em todos os níveis, também atinge a área da educação, e no caso do objetivo deste trabalho, especificamente o ensino agrícola de $2^{\circ}$ grau. Não quero, portanto, analisar que a extinção da COAGRI advenha dessa transformação como simples resultado, e sim como mais uma determinação que ajuda a compreender a extensão da própria reestruturação do capitalismo no campo da produção agrícola.

No bojo de uma série de extinções de instituições vinculadas ao Estado, em 21 de novembro de 1986, o governo de José Sarney edita o Decreto 93.613, eliminando de uma só vez quatro órgãos que integravam a estrutura do Ministério da Educação: o Conselho Nacional de Serviço Social; a Comissão Nacional de Moral e Cívica; a Coordenação de Ensino Agropecuário - COAGRI; e a Delegacia Regional do Distrito Federal.

Na seqüência, são editadas as Portarias 821 e 833, do Gabinete do Ministro da Educação, Jorge Bornhausen, atribuindo à Secretaria de $2^{\circ}$ Grau (SESG) o exercício das funções da extinta COAGRI e vinculando as escolas agrotécnicas federais à nova estrutura, respectivamente.

É interessante notar ainda, que a extinção da COAGRI, em conjunto com a Comissão Nacional de Moral e Cívica, demonstra nitidamente a intenção de respaldar a ação, vinculando tais órgãos ao "atraso" da "máquina" que era movida pelos governos militares. Contudo, não trato, neste artigo, o papel da COAGRI no desenvolvimento do ensino agrícola no país, porém é importante certificar que não há um descolamento entre as reestruturações de ordem econômica e as políticas de formação profissional. No caso do ensino agrícola, o que tento reforçar é que as mudanças na organização da produção, 
que em um momento não prescindiam das funções mais diretas do Estado, e que reforçaram uma maior unidade entre a lógica capitalista no campo e na cidade, ao se reestruturar não precisariam mais de um órgão específico para a elaboração de políticas voltadas à formação de técnicos agrícolas, já que depois dessa "unidade estrutural" o mais "adequado" seria tratar tal modalidade de ensino na totalidade dos cursos de formação profissional, sejam eles ligados à indústria, ao comércio ou agricultura.

Entendo, portanto, que esta reestruturação venha se dando de forma contínua, ou seja, ela ainda se encontra em processo, e que sua expressão mais atual seja a recente transformação de Escolas Agrotécnicas Federais em Centros Federais de Educação Tecnológica (CEFETs).[xv]

\section{Breve conclusão}

Observamos com este trabalho, como a estrutura econômica interfere diretamente nas questões superestruturais, e essa fase do ensino agrícola expressou claramente uma determinação dessa interferência.

Dessa forma, o processo de industrialização da agricultura, também apelidado de revolução verde, guardou algumas características específicas, ou seja, o desenvolvimento das forças produtivas no campo, ocorrido a partir da década de 1960, inseriram no processo de produção agropecuária novas exigências de aumento da produtividade, calcada na incorporação de insumos industrializados. Trazendo para o campo da educação a exigência de criação de um órgão central que fosse responsável por controlar e estabelecer novos parâmetros de formação de técnicos habilitados para estas novas demandas.

Nesta mesma perspectiva, a extinção da COAGRI ocorreu como resultado de um novo processo de reestruturação do capitalismo. Reestruturação, agora, de cunho neoliberal.

Assim, este artigo procurou demonstrar que as mudanças ocorridas no campo da educação agrícola não podem ser vistas de forma isolada, e que as mesmas servem para compreendermos melhor as transformações do próprio sistema capitalista e vice-versa.

\section{Referências bibliográficas}

BESKOW, Paulo Roberto. Agricultura e Capitalismo no Brasil. In: Encontros com a civilização Brasileira, Rio de Janeiro, Civilização Brasileira, p.19, 1980.

BRASIL.Decreto no 72.434, de 9 de julho de 1973. Cria a Coordenação Nacional do Ensino Agrícola - COAGRI - no Ministério da Educação e Cultura, atribuindo-Ihe autonomia administrativa e financeira e dá outras providências. Brasília, 1973.

. Decreto $n^{\circ}$ 76.436, de 14 de outubro de 1975. Altera o Decreto $n^{\circ}$ 72.434, de 9 
de julho de 1973, que criou a Coordenação Nacional do Ensino Agropecuário do Ministério da Educação e Cultura. Brasília, 1975.

. Decreto no 93.613, de 21 de novembro de 1986. Extingue órgãos do Ministério da Educação, e dá outras providências. Brasília, 1986.

BRASIL/MEC. Portaria do Gabinete do Ministro no 217, de 16 de abril de 1974.Institui grupo tarefa para implantação da COAGRI e dá outras providências. Brasília, 1974.

Portaria do Gabinete do Ministro no 821, de 26 de novembro de 1986.Atribui a Secretaria de Ensino de 2ํㅡㅁ ${ }^{\circ}$ exercício das funções da COAGRI. Brasília, 1986.

Portaria do Gabinete do Ministro no 833, de 01 de dezembro de 1986. Vincula as Escolas Agrotécnicas Federais a SESG. Brasília, 1986.

DELGADO, Guilherme da Costa. Capital Financeiro e Agricultura no Brasil. Ícone Editora/Editora da UNICAMP, São Paulo/Campinas, 1985.

Expansão e modernização do setor agropecuário no pós-guerra: um estudo da reflexão agrária. Estudos Avançados 15 (43), 2001. Acessado em http://www.scielo.br/pdf/ea/v15n43/v15n43a13.pdf, em 17 de maio de 2006.

FRIGOTTO, Gaudêncio. A produtividade da escola improdutiva. Cortez Editora/Editora Autores Associados, São Paulo, 1986.

KAGEYAMA, Ângela et. alii.(Coord.). O novo padrão agrícola brasileiro: do complexo rural aos complexos agroindustriais. In: DELGADO, G. da Costa; GASQUES, J.G.; VILLA VERDE, C. Agricultura e políticas públicas (p.113 - 223). Brasília: Ipea, 1990.

PEDRÃO, Fernando. As transformações rurais do capital no Brasil.BAHIA ANÁLISE \& DADOS, Salvador, v13, n4 (p.819-831), mar. 2004.

MAZZALI, Leonel. O processo recente de reorganização agroindustrial: do complexo à organização "em rede". Editora UNESP, São Paulo, 2000.

NAVARRO, Zander. Desenvolvimento rural no Brasil: os limites do passado e os caminhos do futuro. Estudos Avançados 15 (43), 2001. Acessado em http://www.scielo.br/pdf/ea/v15n43/v15n43a09.pdf, em 17 de maio de 2006.

SAMPAIO, Plínio. Capital Estrangeiro e Agricultura no Brasil. Vozes, Petrópolis, 1980.

SANTOS, Aparecida de Fátima Tiradentes dos. Teoria do Capital Intelectual e Teoria do Capital Humano: Estado, Capital e Trabalho na política educacional em dois momentos do processo de acumulação. GT: Trabalho e Educação, 27ª Reunião Anual da ANPED, Caxambu, 2004.

SOARES, Ana Maria Dantas. Formação de técnicos em Agropecuária: currículos como instrumento de políticas públicas de regulação. GT: Trabalho e Educação, 27ª Reunião Anual da ANPED, Caxambu, 2004.

VEIGA, José Eli da. Quatro observações sobre o nexo entre mudança técnica e reestruturação agroindustrial. Anais do Seminário sobre mudança técnica e reestruturação agroindustrial, NPCT-UNICAMP, Campinas, 1990.

Destinos da ruralidade no processo de globalização. Estudos Avançados. 18 (51), 2004. Acessado em http://www.scielo.br/pdf/ea/v18n51/a03v1851.pdf , em 19 de 
maio de 2006.

Territórios para um desenvolvimento sustentável. Revista Ciência e Cultura (SBPC), ano 58, no 1; jan/fev/março, 2006a.

A atualidade da contradição urbano-rural. Acessado em http://www.sei.ba.gov.br/publicacoes/publicacoes_sei/bahia analise/sep/pdf/sep/pdf/s€ em 19 de maio de 2006b.

[i] Coordenação de Ensino Agropecuário, órgão do Ministério da Educação responsável pela elaboração e acompanhamento da política do ensino agrícola.Criada definitivamente em 1975 e extinta em 1986.

[ii] Professor do Colégio Agrícola Nilo Peçanha/UFF. Mestre em Educação pelo Programa de Pós Graduação em Educação/UFF. Membro do Núcleo de Estudos e Documentação em Trabalho e Educação/UFF.

[iii] Nunca é demais lembrar que o processo de modernização não alcançou grande parte da agricultura brasileira, portanto, ainda hoje há um abismo muito grande entre as diversas formas de se produzir; convivem em um mesmo período histórico o "atrasado" e o "moderno", afinal as diferenças de classe também se materializam no campo. Mas por que neste trabalho trato somente de uma parte deste processo excludente de "modernização"? Por entender que ele é quem estabelece as demandas por profissionais para a agricultura, materializando-as nas políticas de Estado.

[iv] Embora os trabalhos de José Eli da Veiga (1990, 2004, 2006a e 2006b), contestem o conceito de industrialização da agricultura, e mesmo concordando com seus argumentos, usarei tal conceito neste trabalho por entender que o referido autor trata basicamente de questões ligadas ao ambiente rural. Como neste artigo a perspectiva de análise esta centrada nos processos de produção, entendo que, assim como os autores que serão citados, este conceito se aplica como forma de demonstrar a penetração da lógica capitalista industrial na produção agrícola brasileira, principalmente do ponto de vista da organização da produção.

[v] Alicerçada no que foi genericamente intitulado de 'revolução verde', materializou-se de fato sob um padrão tecnológico o qual, onde foi implantado de forma significativa, rompeu radicalmente com o passado por integrar fortemente as famílias rurais a novas formas de racionalidade produtiva, mercantilizando gradualmente a vida social e, em lento processo histórico, quebrando a relativa autonomia setorial que em outros tempos a agricultura teria experimentado. Com a disseminação de tal padrão na agricultura, desde então chamado de 'moderno', o mundo rural passou a subordinar-se, como mera peça dependente, a novos interesses, classes e formas de vida e de consumo, majoritariamente urbanas, que a expansão econômica do período ensejou, em graus variados, nos diferentes países. Esse período, que coincide com a impressionante expansão capitalista dos 'anos dourados' (1950-1975), é assim um divisor de águas também para as atividades agrícolas, e o mundo rural (re)nasceria fortemente transformado, tão logo os efeitos desta época de transformações tornaram-se completos.(NAVARRO, 2001, p.84).

[vi] A mudança da base técnica da agricultura assentou-se em um conjunto de inovações mecânicas, físicoquímicas e biológicas, que tinham por referência os princípios técnicos da chamada 'Revolução Verde', 'que combina inovações físico-químicas e mecânicas com a criação de variedades vegetais altamente exigentes em adubação química e irrigação...'(Delgado, 1985, apud. Mazzali, 2000, p.20)

[vii] Como expõe Delgado (1985), em tabela demonstrativa. (p.40)

[viii] Para melhor compreensão desse processo, recomendo Delgado (1985 e 2001) e Kageyama et. alii (1990).

Plínio Sampaio (1980), apresenta um outro aspecto importante desse processo de reestruturação da agricultura brasileira, que é o deslocamento de capital estrangeiro já nas décadas de 1960 e 1970, para a aquisição de grandes propriedades rurais por empresas que aparentemente não eram especializadas no setor, como por exemplo: grandes bancos, montadoras de automóveis, seguradoras, etc.

"A produção de mercadorias agrícolas sempre foi uma das principais bases da economia internacional, mas 
a nova internacionalização do capital, na segunda metade do século $X X$, moveu-se sobre a economia rural a partir de alterações da produção industrial, que procurou controlar o mercado de insumos e de equipamentos agrícolas, bem como o mercado de consumo da população rural. A nova internacionalização do capital moveu-se de determinados modos específicos na economia rural, ampliando a participação do capital mercantil internacional, ..." (PEDRÃO, 2004, p.820.

[ix] Segundo Kageyama et. alii (1990), entre 1970 e 1979, a disponibilidade de crédito cresceu 329\% em termos reais (p.161).

[x] Extensão Rural é, basicamente, a estrutura responsável em fazer a difusão das inovações do processo de produção agrícola na comunidade rural. Pretende ser o braço entre a academia e o campo.

[xi] Eficácia, eficiência e efetividade eram as noções predominantes à época, muito próximas dos princípios da Teoria do Capital Humano, quais sejam, racionalidade, eficiência e produtividade, sendo o pressuposto básico da tendência tecnicista o da neutralidade científica. Falava-se em instrumentalizar os alunos para a realização de operações e buscava-se uniformizar as experiências pedagógicas, com modelos curriculares produzidos por especialistas a partir de seus laboratórios. A lógica do mercado passa a fundamentar 0 direcionamento escolar, o que exige uma articulação do sistema educativo com o sistema produtivo, onde o primeiro deve responder às demandas do segundo. Esse enfoque tecnicista vai influenciar profundamente a Reforma educacional implementada com a Lei 5.692/71, que propugnava a profissionalização compulsória em nível de $2^{\circ}$ grau, voltada para atender às necessidades do desenvolvimento econômico daquele período histórico.(SOARES, p.2, 2004).

[xii] Se tomarmos como base o trabalho de Lénine (1975), veremos que a perspectiva do domínio de um mercado financeiro não é nada recente, mas dadas às condições construídas historicamente, ou, se avaliarmos o próprio processo do capitalismo, tendo como uma de suas fases o modo de acumulação fordista aliado ao welfare state, poderemos então reforçar a análise de que o setor financeiro nunca foi tão hegemônico como tem sido nas duas últimas décadas.

[xiii] No campo da produção de Zebuínos, por exemplo, o Brasil se coloca como expoente mundial e referência nas técnicas de melhoramento genético dessa área específica da bovinocultura. Tendo como resultado animais que superam, em muito, nos aspectos de conversão alimentar e conformação de carcaça, os próprios indianos, de onde originam-se essas raças.

[xiv] No decorrer de seu trabalho, Mazzali irá demonstrar como ocorreu, portanto, uma reorientação na organização e no sentido do comportamento dos agentes ligados a agroindústria, por isso, defende que o conceito de complexo agroindustrial não é mais capaz de explicar essa reorganização que ele denomina de "organização em rede", reflexo, portanto, do processo de flexibilização na agroindústria. Assim, para demonstrar sua tese, ele usa como objeto empírico a organização na cadeia soja/óleos/carnes e na agroindústria citrícola.

[xv] Nos levantamentos que fiz, observei que, pelo menos, dez escolas agrotécnicas federais foram transformadas em CEFETs, entre 1999 e 2002. Foram elas: Escola Agrotécnica Federal de Rio Verde-GO, Escola Agrotécnica Federal de Urutaí-GO, Escola Agrotécnica Federal de Morrinhos-GO, Escola Agrotécnica Federal de Bambuí-MG, Escola Agrotécnica Federal de Januária-MG, Escola Agrotécnica Federal de Rio Pomba-MG, Escola Agrotécnica Federal de Uberaba-MG, Escola Agrotécnica Federal de Cuiabá-MT, Escola Agrotécnica Federal de Petrolina-PE e Escola Agrotécnica Federal J.K. (Bento Gonçalves-RS)

\section{volta}

